10. Altyn Esbulatova, Kirill VOINOV. How Can Live Together Very Old Owner And His Beloved Dog. RAS MEDICAL SCIENCE, Issue Type: Volume 1, Issue 1. - 5 pages.

11. Kirill Voinov, Altyn Esbulatova. Water as our life and Helper. Juniper Publishers. Annals of Reviews and Research, Volume 5, Issue 5 - July 2020. DOI: 10.19080/ARR.2020.05.555673. - 4 pages.

12. Kirill Voinov, Altyn Esbulatova. Novelties Connected With Lubricants. Journal of Multidisciplinary Engineering Science and Technology (JMEST), ISSN: 2458-9403. Vol. 6, Issue 1, January - 2019. (9379-9383). - 5 pages.

13. $\mathrm{Xu}$ Fang, Kirill Voinov, Altyn Esbulatova. Results of Investigations and Recommendations How to Reduce Excessive Weight in People. ICECBB, Dec. 2019, SCI Journal Publishing. International conference and Exhibition on Computational Biology and Bioinformatics. Lausent, Taiwan, 2019. http://www.icecbb2019.org/index.htm

\title{
Kurysheva E.S. \\ The main stages of the process of formation and development of inclusive education in the United States in the context of multicultural educational policy
}

Volgograd State Pedagogical University (Russia, Volgograd)

doi: $10.18411 / s r-10-04-2021-67$

Information about funding sources or grants:

The research was carried out with the financial support of the Russian Foundation for Basic Research in the framework of research project No. 19-313-90028 (the topic "Formation and development of inclusive education in modern secondary schools in the United States in the context of multicultural education policy").

\section{Abstract}

This article identifies the main stages of the formation of inclusive education (segregative, integrative, inclusive), reveals the evolutionary nature of inclusive education. The article analyzes the content of the main document regulating the right to education of children with alternative development - The Law on Education of Persons with Disabilities (1975).

Keywords: inclusion, inclusive education, integration, segregation, periods of development of inclusive education.

The United States, a country of cultural, ethnic, linguistic, religious, and social diversity, has a long tradition of research and practice in special education and inclusive practices. A retrospective analysis of the process of formation and development of inclusive education in the United States allows us to divide it into the following main periods: segregative (until the 1970s); integrative (1970s-1980s); inclusive (from the late 1980s to the present).

Let us consider briefly the main historical moments in each of these periods, as a result of which the system of training of persons with alternative development underwent reform.

The segregative period (until the 1970s). According to the historians of American education (L. Wagoner, Jr. [2], Wayne J. Smith, Jr. Urban [2], Reese William John [9], J. Rury [9], J. Wayne [9]), the period between 1900 and the 1970s is called the phase of segregation or isolation. People with developmental disabilities have been isolated from their ordinary fellow citizens for centuries. The first law in the country concerning persons with disabilities was passed in 1798.

In the first half of the 20th century, the laws on compulsory universal school attendance for children under 16 were not applicable to students with disabilities. The period from 1820 to 1920 is called by historians the time of the adoption of important laws on compulsory education in the country, among which are The Law on the Provision of Free 
Education (1821), the Dawes Act (1887) (Dawes Act, 1887) [11], the Smith-Towner Bill (1919) (Smith-Towner Bill, 1919) [10].

Until the mid-1970s, U.S. federal education laws gave local school districts the right to refuse admission to public schools for children with any (even minor) degree of developmental abnormality.

As researchers point out (B. Conley [3], N. Noddings [8]), special education for alternative children took place until the mid-1970s, but it meant the segregation of students into separate schools. The formation of the education system for special children in the United States is closely interrelated with the development and consolidation of the status of multicultural education as the main vector in the country's educational policy, the history of which is considered in detail in the works by I. S. Bessarabova [1]. Since the middle of the twentieth century, as a result of the active movement in society for the rights of citizens, the situation of children and adults with alternative development has significantly improved.

The next period in the history of inclusive education in the United States is the integrative period (1970 - 1980s). The Law on the Education of Persons with Disabilities, which entered into force in 1975, is the main document of this period, which marked a new stage of reforms in the system of education of persons with alternative development [12].

The study of the content of the Law allows us to distinguish four main sections. The first section is devoted to general provisions, concepts and goals. The law emphasizes that children with disabilities should be taught together with their peers who have a traditional development, as far as possible, if the degree of violation of the child's health does not pose a threat to the safety of others. The second section of the Law includes provisions on secondary education, pre-school education for children from 3 to 5 years old, individualized training programs, as well as measures to protect the rights to education of this group of citizens in court. The third section of the Law is devoted to the norms of early intervention, or services intended for children under 3 years of age according to an individual family support plan. The fourth section of the Law is devoted to the issues of personnel training, technical equipment, and conducting scientific research on the training of persons with special needs.

The purpose of the Law is to ensure that all children with disabilities are entitled to appropriate free public education, which also includes special education and related services designed to meet their individual learning needs.

Let us turn to the main important points of the Law on Education for Persons with Disabilities. The law emphasizes the responsibility of each state to ensure the proper quality of education for citizens. The main principles of the Law include:

1. Schools are required to teach all children with disabilities. This principle applies regardless of the nature or severity of the child's alternative. This principle states that no child with developmental disabilities should be excluded from a public school.

2. Fair identification and evaluation. The law requires that alternative students are evaluated fairly. According to the scientists, this requirement is especially important because of the presence of non-English-speaking children of color in society, who are identified as failing on the basis of the results of standardized intelligence tests [4].

3. Free appropriate public education. All children with special needs, regardless of the type and severity of the alternative, receive free public education. Individual learning programmes should be developed and implemented for each child. Each program must include a team that includes parents (or guardians), one (or more) general education teacher, special education teacher, psychologist, doctor, local school district representative, and child.

So, children with alternative development got the right to co-education with traditional children thanks to the Law, which meant their integration into regular schools. Since the 
second half of the 1970s, such co-education has been called integrated, the essence of which was that the alternative child was placed in a regular class. At the same time, there was no special approach to a special child on the part of the school team of adults and peers, except for the help of one teacher, in whose class such a student was found. If the child continued to experience learning difficulties and did not complete their program, they were transferred to individual home schooling.

However, the need for integrated learning is unanimously recognized by many scientists, despite the noticeable limitations of this form [6]. Integrated learning was a gentle transition from segregation to inclusion, clearly defining the main essence of the inclusive approach, which is that it is not the child who must adapt to the external conditions, but, on the contrary, the external environment must be adapted to the needs and capabilities of the child.

In the 1980s, scientists - supporters of multicultural education - analyzing the limitations of integrated learning, continue to search for new forms and methods of teaching children with alternative development. In this regard, the works of J. Bruner, J. Banks, J. Gay, G. Ladson-Billings, K. Grant, and others should be noted [1]. During this period, in the pedagogical literature of the United States, the concept of "alternative in development" begins to be interpreted more widely, and includes not only children with developmental disabilities, but also children who experience learning difficulties due to lack of preparation for school due to a dysfunctional family situation.

In the 1980s, scientists raised the problem of the negative impact of poverty on school performance. J. Bruner introduces the special term "culture of poverty". Scientists began to refer homeless children to the alternative children, as well as those whose parents are lowincome, unemployed, disadvantaged, or migrants without a permanent place of residence and work, and, consequently, not socially adapted.

In 1987, a special law on assistance to homeless persons (Homeless Assistance Act, 1987) came into force, including the issues of education for this group of citizens. The introduction of this Law marked the beginning of an inclusive period (from the late 1980s to the present) in the history of American education.

Researchers emphasize unanimously that ensuring the full growth and development of children will be possible in an inclusive educational environment, which requires changes in the school system [5]. Inclusive learning in an inclusive educational environment makes the learning process accessible to all students, as it combines a general approach with a special approach to the child, meeting the various educational needs of children.

The law "No child left behind", which came into force in 2001, increased the attention of the entire nation to the problem of school performance and discipline, giving these issues state significance [7]. No Child Left Behind (NCLB) mandates that U.S. schools are responsible for the educational outcomes of all students, including children with alternative development. The latest updated version of the Law on the Education of Persons with Disabilities, approved in 2004, includes most of the requirements for the educational conditions of special children, borrowed from this law [12]. In general, the Homeless Assistance Act of 1987, together with the two above-mentioned laws, firmly established the right of all American children to be included in the general education class to the maximum extent possible.

Thus, in accordance with the results of a retrospective analysis of the formation and development of the inclusive education system in the United States, its evolutionary nature is revealed, which is characterized by a gradual transition from a period of segregation with complete isolation of children in special institutions (until the mid-1970s) to an integrative period with access of alternative students to regular schools, but with the preservation of external barriers to knowledge acquisition (mid-1970s - the end of the 1980s) and then to the inclusive period, which provides for the co-education of children with alternative and 
traditional development in an inclusive educational environment (the end of the 1980s to the present).

$$
* * *
$$

1. Bessarabova I. S. Multicultural education in Russia and abroad: textbook. manual / I. S. Bessarabova, I. I. Skachkova, A.V. Kobzar. - Volgograd: Publishing House of the Volgograd Branch of the RANEPA, 2013. $215 \mathrm{p}$.

2. American Education: A History by Jennings L. Wagoner Jr. and Wayne J. Urban. New Edition, 2008. P. 45 .

3. Conley B. Alternative Schools: A Reference Handbook. Santa Barbara, California: ABC CLIO, 2002. $274 \mathrm{p}$.

4. Gardner H. Multiple intelligences: The theory into practice/ H. Gardner. New York: Basic Books, 2015. $125 \mathrm{p}$.

5. Hyatt K.J., Filler J. LRE Re-examined: Misinterpretations and unintended consequences. International Journal of Inclusive Education, 15(9), 2011. P.1031-1045.

6. Kellough A.S. Integrating math and science for intermediate and middle school students/ A.S. Kellough. Englewood Cliffs, NJ: Prentice-Hall/Merrill, 2020. 150 p.

7. No Child Left Behind Act, 2001. [Electronic resource]: http://topics.nytimes.com/top/reference/timestopics/subjects/n/no_child_left_behind_act/index.html?scp= 1 spot\&sq=no\%20 child $\% 20$ left $\% 20$ behind $\% 20$ act $\&$ st $=$ cse

8. Noddings N. The challenge to care in schools: An alternative approach to education/ N. Noddings. New York: Teachers College Press, 2002. 316 p.

9. Rethinking the history of American education / Ed. By W. J. Reese,J. L. Rury. New York: Palgrave Macmillan, 2008. 292 p.

10. Smith-Towner Bill, 1919. [Electronic resource]: https://archive.org/details/jstor994235/page/n1/mode/2up

11. The Dawes 1887. Act
[Electronic resource]: http://www.pbs.org/weta/thewest/resources/archives/eight/dawes.htm

12. U. S. Individuals with Disabilities Education Act (IDEA). [Electronic resource]:https://sites.ed.gov/idea/

\section{Liu Tse \\ Principles of organization and methods of patriotic education of students by means of vocal art in the People's Republic of China}

Volgograd state socio-pedagogical University

(Russia, Volgograd)

doi: $10.18411 / s r-10-04-2021-68$

\section{Abstract}

The relevance of the topic of the article is due to the importance of patriotic education of students in modern Chinese schools. The purpose of this article is to identify and characterize the leading principles of the organization of the educational process by means of vocal art, as well as the methods used by Chinese music teachers in the process of music classes.

Key words: educational vocal repertoire, traditional music culture of China, the value attitude to the musical culture of China, musical-theoretical and musical-historical knowledge, students' creative potential, the world of Chinese folk music and song, cultural analysis of Chinese musical art, dialogue of artistic traditions of Russia and China.

Modern Chinese scientists and music teachers (Yuan Pingping, Hou Wei) recommend to start preparing for music classes at school with the correct selection of the educational vocal repertoire, taking into account the school age of students $[1 ; 2]$. Songs intended for children are a kind of vocal genre and have a number of distinctive features that a school teacher must know in order to organize work with children, and teach them not only new songs and knowledge about folk and foreign music, but also to form an aesthetic taste, moral values, patriotic qualities of a growing personality through vocal works. Researcher Su Liyan 